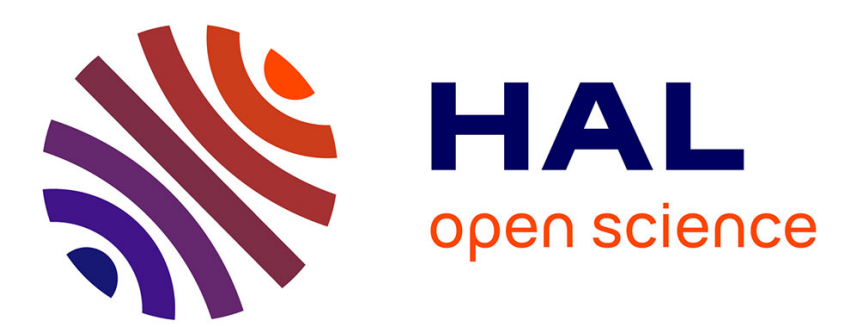

\title{
Kinetic Modeling of VOC Photocatalytic Degradation Using a Process at Different Reactor Configurations and Scales
}

Aymen Amine Assadi, Abdelkrim Bouzaza, Dominique Wolbert

\section{- To cite this version:}

Aymen Amine Assadi, Abdelkrim Bouzaza, Dominique Wolbert. Kinetic Modeling of VOC Photocatalytic Degradation Using a Process at Different Reactor Configurations and Scales. International Journal of Chemical Reactor Engineering, 2016, 14 (1), pp.395-405. 10.1515/ijcre-2015-0003 . hal01298764

HAL Id: hal-01298764

https://hal-univ-rennes1.archives-ouvertes.fr/hal-01298764

Submitted on 5 Jul 2016

HAL is a multi-disciplinary open access archive for the deposit and dissemination of scientific research documents, whether they are published or not. The documents may come from teaching and research institutions in France or abroad, or from public or private research centers.
L'archive ouverte pluridisciplinaire HAL, est destinée au dépôt et à la diffusion de documents scientifiques de niveau recherche, publiés ou non, émanant des établissements d'enseignement et de recherche français ou étrangers, des laboratoires publics ou privés. 


\title{
Kinetic modelling of VOC photocatalytic degradation using a process at different reactors configurations and scales
}

\author{
ASSADI Aymen Amine ${ }^{a . b *}$, BOUZAZA Abdelkrim a,b, WOLBERT Dominique a,b \\ ${ }^{a}$ Laboratoire Sciences Chimiques de Rennes - équipe Chimie et Ingénierie des Procédés, UMR 6226 \\ CNRS, ENSCR-11, allée de Beaulieu, CS 508307-35708 Rennes, France. \\ ${ }^{\mathrm{b}}$ Université Européenne de Bretagne. \\ * Corresponding author. Tel.: +332 23238056; fax: +33 223238120. \\ E-mail address: Aymen.assadi@ensc-rennes.fr (A. ASSADI).
}

\begin{abstract}
This work investigated the performance of Isovaleraldehyde (3-methylbutanal) removal from gas streams in photocatalytic reactors at room temperature. The feasibility of pollutant removal using the up-scaled reactor was systematical assessed by monitoring the removal efficiency at different operational parameters, such as geometries of reactor, air flow rate and inlet concentration.

A proposal modeling for scaling-up the photocatalytic reactors is described and detailed in this present study. In this context, the photocatalytic degradation of isovaleraldehyde (Isoval) in gas phase is studied. In fact, the removal rate has been compared at different continuous flow reactors: a photocatalytic tangential reactor (PTR), planar reactor and P5000 pilot. The effects of the inlet concentration, flowrate, geometries and size of reactors on the removal efficiency are also studied. A kinetic model taking into account the mass transfer step is developed. The modeling is done by introducing an equivalent intermediate (EI) formed by the photo-oxidation of Isoval. This new approach has substantially improved the agreement between modeling and experiments with a satisfactory overall description of the mineralization from lab to pilot scales.
\end{abstract}

\section{Keywords}

Kinetic modeling, VOC, mass transfer, scaling-up, photocatalytic reactors

\section{Introduction}

Some industries emit waste gases containing pollutants that might be harmful for the environment, pose public health problems, or cause nuisances [1, 2]. This is the case of animal rendering plants, which generate a variety of highly malodorous pollutants including volatile organic compounds (VOC) and inorganics such as ammonia and sulfur compounds. Some of 
VOCs, e.g. benzene and its derivatives, haloalkanes, formaldehyde, amines etc., are considered to be carcinogenic, mutagenic or teratogenic [3-5].

Unfortunately, the existing treatment processes have their drawbacks. Therefore, there is currently a great deal of interest in developing processes which can degrade these compounds. Among the proposed solutions for the reduction of this pollution, we can cite adsorption [6], biological treatment and, more recently, advanced oxidation processes such as photocatalysis [35, 7-10]. Photocatalysis is an heterogeneous process between a solid phase (catalyst) containing a semiconductor usually titanium dioxide $\left(\mathrm{TiO}_{2}\right)$ and the gas or liquid phase [8-10]

The process is based on the use of low energy UV-A photons to excite a semiconductor catalyst (most usually $\mathrm{TiO}_{2}$ ) leading to formation of electron-hole pairs. The electrons and holes lead to the formation of very reactive hydroxyl radicals in the gas phase $[\mathbf{1 0}, \mathbf{1 1}]$. These last have the ability to destroy many toxic organic pollutants [11].

Moreover, the overall process can be described by the following reaction [12]:

$$
\text { Organic Pollutants }+\mathrm{O}_{2} \stackrel{\text { Semiconductor }+ \text { UVA Light }}{\longrightarrow} \mathrm{CO}_{2}+\mathrm{H}_{2} \mathrm{O}+\text { Mineral Acid }
$$

In order to better understand the photocatalytic process, different prediction models have been developed. In most of the studies found in the literature [18-21, 38, 39], the LangmuirHinshelwood (L-H) equation has been used to describe the initial concentration rate (eq.1)

$$
-r_{0}=k \cdot \theta=k \cdot \frac{K \cdot C_{0}}{\left(1+K . C_{0}\right)}
$$

where $\theta$ is the fractional surface coverage, which can be expressed by Langmuir's relation. $\mathrm{K}$ $\left(\mathrm{m}^{3} \mathrm{~mol}^{-1}\right)$ and $\mathrm{k}\left(\mathrm{mol} \mathrm{m}^{-3} \mathrm{~s}^{-1}\right)$ are the binding constant and the apparent reaction kinetic constant and $\mathrm{C}_{0}\left(\mathrm{~mol} \mathrm{~m}^{-3}\right)$ is the initial concentration of the target compound.

A closer look at the fundamental development shows that the expression (1) represents a simplification of a more general L-H kinetic expression that includes the presence of competing species towards the adsorption sites. Each of these species may, in turn, react photocatalytically. A generic L-H formulation, with the competitive Langmuir model, would then be expression (2):

$$
-r_{i}=k_{i} \cdot \theta_{i}=k_{i} \cdot \frac{K_{i} \cdot C_{i}}{1+\sum_{j=1}^{n} K_{j} C_{j}}
$$

where $\mathrm{K}_{\mathrm{i}}\left(\mathrm{m}^{3} \mathrm{~mol}^{-1}\right)$ and $\mathrm{k}_{\mathrm{i}}\left(\mathrm{mol} \mathrm{m} \mathrm{s}^{-1}\right)$ are the binding constant onto the surface of $\mathrm{TiO}_{2}$ and the reaction kinetic constant of the species $j, j \in[1 ; n]$. 
Most reported of them consider mass balance of pollutants in either air or solid phase [10, 13, 14]. Only few models consider pollutants mass balance for both air and solid phase, and those which take it into account assume a steady state condition [15]. Moreover, in his work, Zhang and co-workers [16] reported an interesting approach to the modelling of PCO reactors. Based on the analogy between heat and mass transfer for heat exchangers they developed a reactor model with two parameters, the fractional conversion and the number of mass transfer units [11]. These parameters are supposed to influence the photo-oxidation performance of PCO reactors $[17,18]$.

Here Isovaleraldehyde was chosen since this pollutant was found as the main molecule detected in the exhaust gases from animal quartering centers [2].

This work presents an interesting approach for the modelling of the isovaleraldehyde degradation with using three different continuous reactors: cylindrical reactor, planar reactor and pilot unit. Moreover, this model will be built to account for each part of the experimental setup in order to answer the question of reactors scaling-up.

\section{Set-up}

The experimental units include four major elements: the gas mixture generation system, the catalyst medium, the photocatalytic reactor and the analysis system.

\subsection{Polluted flow generation}

Isovaleraldehyde (Isoval) air stream is supplied by a VOC generator system. First, isovaleraldehyde (liquid) is pressurized with air in a stainless steel tank $(500 \mathrm{~mL})$. After, the it is heated, vaporized and then mixed with a zero-air flow in an especially designed Bronkhorst vaporization/mixing chamber (CEM). The obtained gaseous air/ Isoval mixture is sampled and diluted twice in order to reach the targeted Isoval concentration. In these conditions, the inlet concentrations $\left(\mathrm{C}_{0}\right)$ range from 2 to $10 \mathrm{mg} \cdot \mathrm{m}^{-3} \pm 10 \%$.

the pollutant can be also injected continuously by a syringe / syringe-driver combination through a septum into the gas stream. This system was described in previous works [13]. All experiments are carried out at room temperature $\left(20^{\circ} \mathrm{C} \pm 1^{\circ} \mathrm{C}\right)$ and at relative humidity $(\mathrm{RH})$ equal to $50 \pm 5 \%$. 


\subsection{The catalyst medium}

The used catalytic material is a Glass Fiber Tissue (GFT) coated with 13 g.m $\mathrm{m}^{-2}$ of colloidal silica to ensure the fixation of $13 \mathrm{~g} \cdot \mathrm{m}^{-2}$ of titanium dioxide nanoparticles. Preparation process is precisely described in Ahlstrom Patents [23]. Specific surface area is measured according to BET method and is equal to $20.6 \mathrm{~m}^{2} \cdot \mathrm{g}^{-1}$. The materials consist in $2 \mathrm{~mm}$ thick sheets of woven fibers.

\subsection{Apparatus and Analysis}

a FISONS Gas chromatograph coupled with a flame ionization detector (GC-FID) is used in order to analysis the Isoval conctration. It is performed by a Chrompact FFAP-CB column (25 $\mathrm{m}$ of length $0.32 \mathrm{~mm}$ of external diameter $0.32 \mathrm{~mm}$ ). Nitrogen gas constitutes the mobile phase. The temperature conditions in the oven, the injection chamber and the detector are, respectively, 100,120 and $200{ }^{\circ} \mathrm{C}$.

All injections are performed manually and repeated three times with a syringe of $500 \mu 1$.

\subsection{Continuous flow reactors}

\subsubsection{The photocatalytic cylindrical reactor}

The cylindrical reactor is presented in Fig. 1. It consists of two concentric Pyrex glass tubes with inner and outer diameters equal to 76 and $58 \mathrm{~mm}$ respectively.

The catalyst medium is fixed on the inside wall of the outer glass tube of the reactor. The length of the photocatalyst is $80 \mathrm{~cm}$. The air flows tangentially over the catalyst medium with a flow rates varying from 2 to $10 \mathrm{~m}^{3} \cdot \mathrm{h}^{-1}$ which correspond to gas residence times inside the photocatalytic section ranging from 0.6 to $3 \mathrm{~s}$.

A Philips UV lamp (Cleo performance 80W/10) with a tube length of $150 \mathrm{~cm}$ is placed inside the inner tube. The emission spectrum of this lamp has a maximum at the wavelength of $365 \mathrm{~nm}$. The UV intensity reaching the photocatalyst surface is measured with a radiometric probe at 365 $\mathrm{nm}$ (VLX-3W/CX 365). It is equal to $24 \mathrm{~W} \cdot \mathrm{m}^{2}$.

\section{Fig. 1}

\subsubsection{The photocatalytic planar reactor}


The planar reactor consists of a rectangular cross section $\left(0.135 \times 0.135 \mathrm{~m}^{2}\right)$ and is $1 \mathrm{~m}$ length. It is made by polymethyl methacrylate (PMMA) material. Two plates, $4.10^{-3} \mathrm{~m}$ thickness, are arranged parallel to the length of the reactor. They permit to maintain the catalyst media. The distance between the two plates, which is also called air gap, can be modified. The planar reactor is equipped with eight UV lamps in order to ensure a good radiation distribution (Fig. 2). The length of the irradiated zone is $0.8 \mathrm{~m}$. The photocatalytic support surface is equal to $0.19 \mathrm{~m}^{2}$. The used fluorescent UV lamp (Philips under reference PL-S 9W/10/4P, 0.012 m bulb diameter, 0.135 m bulb length) has a major wavelength peak emission at $355 \mathrm{~nm}$. The centerlines of the lamps are separated by $0.01 \mathrm{~m}$. Each lamp is connected to a separate switch (see Fig.2). This permit to control the delivered UV intensity.

Fig.2.

In order to supply the planar and cylindrical reactors, a centrifugal pump is used with ambient air. The flow rate is controlled by a flow meter (Bronkhorst In-Flow type E-700. AAA). A detailed description of the device was given previously [18, 21].

\subsubsection{Pilot unit}

This reactor is an air handling unit produced by CIAT (Compagnie Industrielle d'Applications Thermiques - France) with a flow rate capacity up to $5000 \mathrm{~m}^{3} \cdot \mathrm{h}^{-1}$ (Fig. 3). Inside used material is $316 \mathrm{~L}$ stainless steel which is able to withstand corrosion induced by the most corrosive chemical compounds. The unit comprises a pre-filtration box, a cooling bank, an electric heater (box no. 1), a vapour humidifier (box no. 2), a pollutant injection area (box no. 4), an upstream pollution measurement box, a photocatalytic treatment system, a downstream concentration measurement box (box no. 5); a fan (box no. 6) and finally an activated carbon filtration (box no. 7).

The photocatalytic zone has a cross-section area $(0.61 \mathrm{~m} * 0.61 \mathrm{~m})$. It contains the photocatalytic pleated media offering a surface of $2.16 \mathrm{~m}^{2}$ and 36 Philips UV lamps (PL-L 24W/827/4P). The ventilation box consists of a medium-pressure centrifugal fan. This scroll-free fan is coupled directly to a $3 \mathrm{~kW}$ motor. The assembly is driven by a frequency generator.

The air flow passing through the pilot unit is quantified via a pressure drop measure on either side of a diaphragm.

\section{Fig.3}


The Removal efficiency of Isoval during each experiment is calculated with the average concentrations of contaminant in the inlet and the outlet gas when steady-state values are reached (after 1-2 h). Gas samples are taken every 10-15 min and the steady-state is kept during $2 \mathrm{~h}$ at least.

The photocatalytic system of pilot unit is showed in figure. 4 .

Fig. 4

After the adsorption process reaches equilibrium (depending upon the nature of the VOC, the flowrate and the concentration), as indicated by identical inlet/outlet VOC concentration, the UV illumination is turned on. The outlet gas is then sampled manually at regular intervals until a new steady state is achieved about 30-60 min.

After completing the experiments, the reactor is flushed under UV illumination for $1 \mathrm{~h}$ using clean air.

No deactivation is observed after a week period of operation.

\section{Modelling and kinetic results}

The main purpose of this work is to establish a predicting model which can be applied to the design of photocatalytic reactors.

\subsection{Mathematical model of the process}

In order to answer the question of scaling-up of reactors, a kinetic model is developed taking into account the mass transfer step to describe the isovaleraldehyde photocatalytic degradation.

\subsubsection{Mass balance in the reactor}

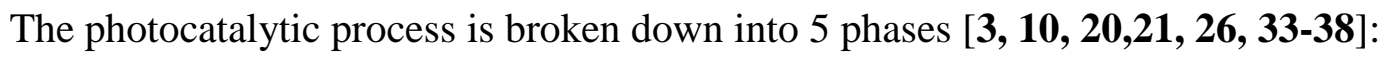

- Transfer of gaseous reagents to the photocatalytic surface

- Adsorption of gaseous reagents on the photocatalytic surface (Fig.5)

- Photochemical reaction between gaseous reagents adsorbed on the photocatalytic surface; mineralisation of organic compounds

- Desorption of gaseous photocatalytic reaction products

- Diffusion of gaseous products from the photocatalytic surface. 


\section{Fig. 5}

The mass balance in the bulk phase (Eq. (3)) and solid phase (Eq. (4)) can be written as:

$$
\begin{aligned}
& \frac{\partial C_{i}}{\partial t}+u \cdot \frac{\partial C_{i}}{\partial x}=\frac{k_{f}}{y} \cdot\left(C_{s, i}-C_{i}\right) \\
& \frac{\partial q_{s, i}}{\partial t}=-\frac{k_{f}}{m_{c}} \cdot\left(C_{s, i}-C_{i}\right)-r\left(q_{s, i}\right)
\end{aligned}
$$

Where $\mathrm{u}$ is the velocity of flow $\left(\mathrm{m} \cdot \mathrm{s}^{-1}\right), \mathrm{C}_{\mathrm{i}}$ is the concentration of any compound $\mathrm{i}$ in the bulk; $\mathrm{k}_{\mathrm{f}}$ is mass transfer coefficient $\left(\mathrm{m} . \mathrm{s}^{-1}\right)$; $\mathrm{m}_{\mathrm{c}}$ is the real mass of $\mathrm{TiO}_{2}$ coated on the fiber $\left(\mathrm{g} \cdot \mathrm{m}^{-2}\right) . \mathrm{k}_{\mathrm{f}}$ is the coefficient of mass transfer between bulk and solid phase. $\mathrm{C}_{\mathrm{s}, \mathrm{i}}$ would be the concentration adsorbed on catalyst at equilibrium $\left(\mathrm{mol} . \mathrm{m}^{-3}\right)$ with the adsorption capacity $\mathrm{q}\left(\mathrm{mol} . \mathrm{g}^{-1}\right.$ ) considering the Langmuir model (eq.5), where $\mathrm{q}_{\mathrm{m}, \mathrm{i}}$ is the maximum adsorption capacity onto the solid (mol. $\left.\mathrm{g}^{-1}\right)$ and $\mathrm{K}$ is a binding adsorption constant $\left(\mathrm{m}^{3} \cdot \mathrm{mol}^{-1}\right)$. Using the fractional coverage $\theta$ (eq.6), the expression of $\mathrm{C}_{\mathrm{s}, \mathrm{i}}$ can be expressed as eq.7:

$$
\begin{gathered}
C_{s, i}=\frac{\theta_{i}}{K_{i} \cdot\left(1-\sum_{j=1}^{n} \theta_{j}\right)} \\
\theta=\frac{q_{i}}{q_{m, i}} \\
C_{s, i}=\frac{q_{i} / q_{m, i}}{K_{i} \cdot\left(1-\sum_{j=1}^{n}\left(q_{j} / q_{m, j}\right)\right.}
\end{gathered}
$$

\subsubsection{Adsorption isotherm}

The single component adsorption isotherm of isovaleraldehyde is studied. The amounts adsorbed on the catalyst $\mathrm{q}_{\mathrm{s}}\left(\mathrm{mol} . \mathrm{g}^{-1}\right)$, were calculated with Eq. (8):

$$
q_{s}=\frac{C_{0}-C_{s}}{m_{c a t}}
$$

where $\mathrm{C}_{0}$ and $\mathrm{C}_{\mathrm{s}}\left(\mathrm{mol} \cdot \mathrm{m}^{-3}\right)$ are the initial concentration and the concentration at equilibrium, respectively and $\mathrm{m}_{\mathrm{cat}}\left(\mathrm{g} \cdot \mathrm{m}^{-3}\right)$ is the amount of photocatalyst. With our range of inlet concentration, the Langmuir model is valid [6]. The maximal adsorption capacity can be estimated by fitting the model to the experimental data by linearizing $\mathrm{C}_{\mathrm{s}} / \mathrm{q}_{\mathrm{s}}$ versus $\mathrm{C}_{\mathrm{s}}$ : 


$$
\frac{C_{s}}{q_{s}}=\frac{1}{q_{m}}\left(C_{s}+\frac{1}{K}\right)
$$

The following values have been obtained for the isovaleraldehyde: $\mathrm{K}=(6.0 \pm 0.3) \times 10^{3} \mathrm{~m}^{3} \cdot \mathrm{mol}^{-1}$ and $\mathrm{q}_{\mathrm{m}}=(7.2 \pm 0.4) \times 10^{-1} \mathrm{~mol} \cdot \mathrm{kg}^{-1}$.

\subsubsection{Modeling of mass transfer}

On other hand, we assume that the fluid viscosity and density are that of air for mass transfer calculations. The Reynolds number was calculated for flow rates varying from 4 to $10 \mathrm{~m}^{3} \cdot \mathrm{h}^{-1}$, corresponding to Reynolds numbers varying from 400 to 1900 . The flow regime inside the reactor is laminar. This suggests that the mass transfer step may be considered [22].

Thus; during photocatalytic reaction over the immobilized catalyst, both internal and external mass transfer can play significant roles.

The relationship among the observed removal rate, the external and internal mass-transfer rates, and the intrinsic kinetic reaction rate can be considered as a series resistances $[\mathbf{1 7}, \mathbf{3 8}]$ :

$$
\frac{1}{k_{\text {obs }}}=\frac{1}{k_{\text {rea }}}+\frac{1}{k_{m, \text { int }}}+\frac{1}{k_{m, e x t}}
$$

where $\mathrm{k}_{\mathrm{obs}}, \mathrm{k}_{\mathrm{rea}}, \mathrm{k}_{\mathrm{m} \text {,int }}$ and $\mathrm{k}_{\mathrm{m} \text {,ext }}$ are related to the observed removal rate, the intrinsic kinetic reaction rate and the internal and external mass-transfer rates respectively.

The internal mass transfer step limitation is not considered. It should be noted that photocatalysis implies superficial reaction sites; therefore it seems coherent that internal diffusions, either Knudsen or molecular, are negligible [18-20].

Hence the model mass transfer considers only the effect of external mass transfer in the apparent degradation rate for the Eqs. (3) and (4).

Thus, the mass transfer constant $\mathrm{k}_{\mathrm{f}}$ depends only on the flow regime of the fluid and the nature of the gas phase.

Using the planar reactor and pilot unit, it can be evaluated by semi-empirical correlations [30]:

$$
S h=0.664(\operatorname{Re})^{(1 / 2)} \cdot(S c)^{(1 / 3)} \text { for } \operatorname{Re}<10^{5}
$$

For laminar flow in cylindrical reactor, $\mathrm{k}_{\mathrm{m}}$ is determined using a semi-empirical correlation developed by Mobarak et al. [31]:

$$
S h=1,029 \times S c^{0,33} \times \operatorname{Re}^{0.55} \times\left(\frac{L_{t o t}}{d}\right)^{-0,472}
$$


where $L_{\text {tot }}$ is the length of the cylindrical reactor, $d$ is its equivalent diameter, $\mathrm{Sh}, \mathrm{Sc}$ and $\mathrm{Re}$ are respectively dimensionless number of Sherwood, Schmidt and Reynolds.

We use the correlation of Perry et al. [40] to express the molecular diffusivity $\left(D_{m}\right)$ of isovaleraldehyde in the air. The correlation is as follows:

$$
D_{m}=\frac{1.43 \times 10^{-3} \times T^{1.75}}{P\left[\left(\sum v\right)_{A}^{(1 / 3)}+\left(\sum v\right)_{B}^{(1 / 3)}\right]^{2}}\left(\frac{1}{M_{A}}+\frac{1}{M_{B}}\right)^{0.5}
$$

where $\mathrm{P}$ is the pressure of gas stream $(\mathrm{Pa}), \mathrm{T}$ the absolute temperature $(\mathrm{K}) .\left(\sum \mathrm{v}\right)_{\mathrm{A}}$ and $\left(\sum \mathrm{v}\right)_{\mathrm{B}}$ are the molecular volumes of gases $\mathrm{A}$ and $\mathrm{B}$, and $\mathrm{M}_{\mathrm{A}}$ and $\mathrm{M}_{\mathrm{B}}$ are the molecular weights of $\mathrm{A}$ and $\mathrm{B}$ $\left(\mathrm{g} \cdot \mathrm{mol}^{-1}\right)$. The index "A" represents the air stream and " $\mathrm{B}$ "is either isovaleraldehyde.

\subsubsection{Modeling of kinetic reaction}

In this approach, and in order to simplify the modeling work, other parameters, including relative humidity and irradiance, are held constant for the different experiments in this study. Thus, these experiments were performed with a UV irradiance of about $24 \mathrm{~W} \cdot \mathrm{m}^{-2}$.

The kinetic expression selected is then written according to Eq (14).

$$
\mathrm{R}_{\mathrm{i}}(\mathrm{t}, \mathrm{x})=\sum_{\mathrm{j}=1}^{\varphi} \vartheta_{\mathrm{i}, \mathrm{j}} \cdot \mathrm{k}_{\mathrm{j}} \cdot \mathrm{I}(\mathrm{t})^{\gamma_{\mathrm{I}}} \cdot\left(\frac{\mathrm{K} \cdot \mathrm{C}(\mathrm{t}, \mathrm{x}, 0)}{1+\alpha \cdot \mathrm{I}(\mathrm{t})+\mathrm{K} \cdot \mathrm{C}(\mathrm{t}, \mathrm{x}, 0)}\right)^{\gamma_{\mathrm{p}, \mathrm{i}}} \cdot \prod_{\mathrm{p}=1}^{\mathrm{n}-1} \theta_{\mathrm{p}, \mathrm{j}}^{\gamma_{\mathrm{p}, \mathrm{j}}}(\mathrm{t}, \mathrm{x})
$$

where I is the UV intensity of lamp, $\mathrm{C}$ is the concentration of each compound adsorbed on the solid phase, $\mathrm{k}$ and $\mathrm{K}$ are $\mathrm{L}-\mathrm{H}$ constants, $\gamma_{\mathrm{p} ; \mathrm{i}}$ are orders of reaction, and $\vartheta_{\mathrm{i}, \mathrm{j}}$ are the stoechiometric coefficients,

with boundary and initial conditions as follows:

$$
\begin{gathered}
C_{i}(0, x)=C_{0} \\
q(0, x)=0
\end{gathered}
$$

It will always be difficult to perform a complete analysis of all compounds present at any given time; we propose to develop a chemical pathway involving one or more equivalent intermediates (EI). So, we suppose that EI is as a molecule having three carbon atoms $\mathrm{C}_{3}$. For a single EI, the simplified chemical pathway would be:

$$
\text { Isoval } \stackrel{k_{1}}{\longrightarrow} \mathrm{EI} \stackrel{k_{2}}{\longrightarrow} 5 \mathrm{CO}_{2}
$$

The adsorption constants ( $\mathrm{K}$ and $\mathrm{q}_{\mathrm{m}}$ ) of EI having been determined from literature [39]. Then, the following values are $\mathrm{K}=3.6 \times 10^{1} \mathrm{~m}^{3} \cdot \mathrm{mol}^{-1}$ and $\mathrm{q}_{\mathrm{m}}=1.29 \mathrm{~mol} \cdot \mathrm{kg}^{-1}$. 


\subsection{Results and discussion}

The resolution of the partial differential equation set is carried out by using orthogonal collocation [6]. The Gear's predictor-corrector multistep method is applied to the equation set. A Gauss-Newton method is implemented to determinate the values of some parameters, especially, kinetics constants $\left(\mathrm{k}_{\mathrm{j}}\right)$, by a least square fitting of the relative difference between simulated and experimental concentrations.

Figure 6 shows the evolution versus time of the transitory of Isoval oulet concentration and final products resulting from photocatalytic reaction. After $700 \mathrm{~min}$ of contact, the inlet and the outlet concentration of Isoval are the same which means that the photocatalytic medium is saturated. After this adsorption period, the UV lamp is making ON. For reaction times past $300 \mathrm{~min}$, all the concentrations of byproducts are stables.

Fig. 6

Fig. 7 shows the removal rates of Isoval at different inlet concentration and gas flowrates.

For a given flowrate, we note that the removal efficiency decreases proportionally with the inlet concentration. This is due to the availability of the photocatalytic sites at this concentration range. At higher pollutant concentration, the removal efficiency will tend to a limit. As expected, the behavior is similar to what has been reported in the literature for some VOCs [14-16].

Moreover, the increase of flowrate leads also to a decrease of removal efficiency. This can be explained by the fact that the residence time is reduced; the ISOVAL molecules cannot be oxidized. This result is similar to what has been observed in the literature with trichloroethylene (TCE) $[\mathbf{1 0}]$.

Fig. 7

Additionally, the resulting simulations compared to the experimental data are shown in Fig. 8. The model describes reasonably well the ISOVAL removal throughout the experiments and for whatever the initial concentration and the flowrate is. The description of the removal kinetics of isovaleraldehyde by a model with a single EI can sufficiently properly reproduce the degradation of the active substance in the competition for adsorption on to the catalyst between isovaleraldehyde and its intermediate products.

The values of constants $\mathrm{k}_{1}$ and $\mathrm{k}_{2}$ are summarized in Table 1 . These constants $\left(\mathrm{k}_{1} \& \mathrm{k}_{2}\right)$ (see table 1) are similar to the work of hexanal removal by Vuong and co-workers [39]. 


\section{Table 1}

On other hand, we note that the model correlate also successfully the experimental results with planar reactor (Fig.8). The validity of this approach is confirmed with changing section from cylindrical to planar reactor.

\section{Fig. 8}

Fig.9 shows the comparison of simulated result of outlet concentration vs. the experimental data at different flow rates and inlet concentrations using three reactors. We note an agreement between modeling results and experiments with a satisfactory overall description of the ISOVAL removal from the laboratory to pilot scale. Moreover, predicted outlet concentrations compared with experimental results show a root mean square error less than $10 \%$. These results are very convincing, particularly because no adjustable parameters have been used in going from the laboratory reactor to the pilot scale one.

\section{Fig. 9}

\subsection{Overall mineralization}

The $\mathrm{CO}_{2}$ overall selectivity may be a useful parameter to assess the performance of the photocatalytic reactor towards COV removal. It allows estimating the mineralization rate i.e. the ultimate reaction step of the process.

The $\mathrm{CO}_{2}$ overall selectivity is expressed as follow:

$$
\left\{\mathrm{CO}_{2}{ }^{\prime} \text { 's Overall Selectivity }(\%)\right\}_{\text {Isov }}=\frac{\left[\mathrm{CO}_{2}\right]_{\text {isov }}^{\text {out }}-\left[\mathrm{CO}_{2}\right]_{\text {isov }}^{\text {in }}}{5 \times C_{\text {in }} \times \operatorname{IRE}(\%)} \times 10^{4}
$$

where $\left[\mathrm{CO}_{2}\right]_{i s o v}^{\text {in }}$ and $\left[\mathrm{CO}_{2}\right]_{\text {isov }}^{\text {out }}$ refer respectively to the inlet and outlet carbon dioxide concentration in the air. The number 5 represents the stoechiometric coefficient of the overall degradation reaction.

Fig.10 shows Comparison of simulated results of $\mathrm{CO}_{2}$ 's selectivity vs. experimental data at different flowrates and inlet concentrations using three reactors.

Regarding the mineralization, the model is accurate at pilot unit and cylindrical reactor, but tends to overestimate the $\mathrm{CO}_{2}$ formation for planar reactor. It is known that the mineralization of 
complex organic pollutants occurs via several successive reactions. The model with a single EI only accounts for one of these stages, which probably explains the overestimation of the $\mathrm{CO}_{2}$ release. Moreover, the model does not take into account another competitor appearing and disappearing later in the process.

Fig.10

This model describes the degradation mechanism more realistically as a unique value for the rate constant, for constant irradiance and catalyst dose, and can be used for any initial concentration. It can also be used to describe approximately the mineralization, with an average deviation between the experiment and the modeling of about $10 \%$.

Moreover, this simple approach needs to be improved by including another oxidation step before mineralization, in order to simulate more correctly the mineralization kinetic, which remains the key point in designing a photocatalytic reactor.

\section{Conclusion}

We have shown that isovaleraldehyde can be photocatalytically degraded from air with each scale. Photocatalytic degradation of isovaleraldehyde was carried out on three different scale reactors. The feasibility of the scale-up process was demonstrated.

The increase of flowrate leads also to a decrease of removal efficiency. This can be explained by the fact that the residence time is reduced; the molecules of isovaleraldehyde cannot be oxidized. A kinetic model taking into account the mass transfer step is developed. To improve the model concerning mineralization and to describe the removal of the target molecule, we included in the chemical pathway of degradation an equivalent background intermediate product (EI) which was formed directly from the initial compound. In a second reaction, the EI is transformed into $\mathrm{CO}_{2}$. This new approach has substantially improved the agreement between modeling and experiments with a satisfactory overall description of the mineralization, the average error not exceeding $10 \%$. This original approach allows the simulation of photocatalytic kinetics without knowing the complete chemical pathway.

\section{Acknowledgment}


This research was supported by the French National Research Agency (ANR) and the authors wish to thank it. We thank also the Ahlstrom Company which provided us with the photocatalytic medium.

\section{Nomenclature}

r: Average degradation rate $\left(\mathrm{mmol} \cdot \mathrm{m}^{-2} \cdot \mathrm{s}^{-1}\right)$

Q: volumetric flowrate $\left(\mathrm{m}^{3} \cdot \mathrm{s}^{-1}\right)$

$\mathrm{S}$ : catalytic medium surface $\left(\mathrm{m}^{2}\right)$

$\mathrm{k}$ : degradation rate constant $\left(\mathrm{mmol} \cdot \mathrm{m}^{-3} \cdot \mathrm{s}^{-1}\right)$

$\mathrm{K}$ : equilibrium adsorption constant $\left(\mathrm{m}^{3} \cdot \mathrm{mmol}^{-1}\right)$

Re: Reynolds number

Sh: Sherwood number

Sc: Schmidt number

$\mathrm{k}_{\mathrm{m}}$ : mass transfer coefficient $\left(\mathrm{m} . \mathrm{s}^{-1}\right)$

$\mathrm{d}_{\mathrm{eq}}$ : equivalent diameter for the annular reactor $(\mathrm{m})$

$\mathrm{L}_{\text {tot: }}$ length of the reactor $(\mathrm{m})$

D: diffusivity in the air $\left(\mathrm{m}^{2} \mathrm{~s}^{-1}\right)$

av: effective catalyst area per unit volume of reactor $\left(\mathrm{m}^{2} \cdot \mathrm{m}^{-3}\right)$

$\mathrm{C}$ : bulk gas-phase concentration $\left(\mathrm{mmol} . \mathrm{m}^{-3}\right)$

$\mathrm{C}_{\mathrm{s}}$ : medium surface gas-phase concentration $\left(\mathrm{mmol}^{-3} \mathrm{~m}^{-3}\right.$

$\mathrm{P}$ the pressure of gas stream $(\mathrm{Pa})$

$\mathrm{T}$ the absolute temperature $(\mathrm{K})$

$(v)_{\mathrm{A}} /(v)_{\mathrm{B}}$ : molecular volumes of gases $\mathrm{A}$ and $\mathrm{B}$

$\mathrm{M}_{\mathrm{A}} / \mathrm{M}_{\mathrm{B}}$ : molecular weights of $\mathrm{A}$ and $\mathrm{B}\left(\mathrm{g} \cdot \mathrm{mol}^{-1}\right)$

"A": air stream

"B" : isovaleraldehyde

I: intensity of the incident radiation at the lamp $\left(\mathrm{W} . \mathrm{m}^{-2}\right)$

$\Theta_{p}$ : fractional surface coverage

C: concentration of each compound adsorbed on the solid phase,

$\vartheta_{\mathrm{i} ; \mathrm{j}}:$ stoichiometric coefficients.

$\gamma_{\mathrm{p} ; \mathrm{i}} ; \gamma_{\mathrm{I}}$ and $\gamma_{\mathrm{p} ; \mathrm{j}}$ are orders of reaction,

$\varphi$ : number of compounds

$\mathrm{n}_{\mathrm{p}}$ : number of reactions,

$\alpha$ : coefficient of UV intensity. 
$\mathrm{u}:$ the velocity of flow $\left(\mathrm{m} . \mathrm{s}^{-1}\right)$,

$\mathrm{C}_{\mathrm{i}}$ : the concentration of any compound $\mathrm{i}$ in the bulk

$\mathrm{k}_{\mathrm{f}}$ is mass transfer coefficient $\left(\mathrm{m} \cdot \mathrm{s}^{-1}\right)$

$\mathrm{C}_{\mathrm{s}, \mathrm{i}}$ : the concentration adsorbed on catalyst at equilibrium $\left(\mathrm{mol} . \mathrm{m}^{-3}\right)$

$\mathrm{q}$ : the adsorption capacity $\left(\mathrm{mol} \cdot \mathrm{g}^{-1}\right)$

$\mathrm{q}_{\mathrm{m}, \mathrm{i}}$ : the maximum adsorption capacity onto the solid (mol.g $\mathrm{g}^{-1}$ )

$\mathrm{m}_{\text {cat }}$ : the amount of photocatalyst $\left(\mathrm{g} \cdot \mathrm{m}^{-3}\right)$ 


\section{References}

[1] United States Environmental Protection Agency, EPA-456/F-98-005, September 1998

[2] ADEME, Pollutions olfactives : origine, législation, analyse, traitement. Ademe, Dunod, Angers, 2005.

[3] A.A. Assadi, A. Bouzaza, D. Wolbert, Photocatalytic oxidation of Trimethylamine and Isovaleraldehyde in an annular reactor: Influence of the Mass Transfer and the relative humidity. Journal of Photochemistry and Photobiology A: Chemistry 236 (2012) 61-69.

[4] S. B. Kim, H. T. Hwang, S. Ch. Hong, Photocatalytic degradation of volatile organic compounds at the gas-solid interface of a $\mathrm{TiO}_{2}$ photocatalyst, Chemosphere 48 (2002) 437-444.

[5] Sh. Wang, H.M. Ang, M. O. Tade, Volatile organic compounds in indoor environment and photocatalytic oxidation: State of the art. Environment International 33(2007) 694-705.

[6] S. Baup, Elimination de pesticides sur lit de charbon actif en grain en présence de matière organique naturelle : élaboration d'un protocole couplant expériences et calculs numériques afin de simuler les équilibres et les cinétiques compétitifs d'adsorption. Thèse de Doctorat, 2000 Université de Poitiers.

[7] J. Moreira, B. Serrano, A. Ortiz a, H.de Lasa, A unified kinetic model for phenol photocatalytic degradation over $\mathrm{TiO}_{2}$ photocatalysts, Chemical Engineering Science 78 (2012) 186-203.

[8] L. Prieto-Rodriguez, S. Miralles-Cuevas, I. Oller, P. Fernández-Ibánez, A. Agüera, J. Blanco, S. Malato, Optimization of mild solar $\mathrm{TiO}_{2}$ photocatalysis as a tertiary treatment for municipal wastewater treatment plant effluents, Applied Catalysis B: Environmental 128 (2012) 119-125.

[9] A. Maciuca, C. Batiot-Dupeyrat, J-M. Tatibouet, Synergetic effect by coupling photocatalysis with plasma for low VOCs concentration removal from air Applied Catalysis B: Environmental 125 (2012) $432-438$.

[10] E. Moctezuma, E.Leyva, G. Palestino, H.de Lasa, Photocatalytic degradation of methyl parathion: 
Reaction pathways and intermediate reaction products, Journal of Photochemistry and Photobiology A: Chemistry 186 (2007) 71-84.

[11] L. Zhong, F. Haghighat, P. Blondeau, J. Kozinski, Modeling and physical interpretation of photocatalytic oxidation efficiency in indoor air applications, Building and Environment 45 (2010) 26892697.

[12] G. Li, Zh., H. Sun, J. Chen, T. An, B. Li, Pollution profiles, health risk of VOCs and biohazards emitted from Zhang municipal solid waste transfer station and elimination by an integrated biologicalphotocatalytic flow system: A pilot-scale investigation, Journal of Hazardous Materials 250-251 (2013) $147-154$.

[13] N. Petit, , Bouzaza A., Wolbert D., Petit P., Dussaud J., Photocatalytic degradation of gaseous perchloroethylene in continuous flow reactors: Rate enhancement by chlorine radicals, Catalysis Today 124 (2007) 266-272.

[14] V. Tomasic, F. Jovic, Z. Gomzi, Photocatalytic oxidation of toluene in the gas phase: Modeling an annular photocatalytic reactor, Catalysis Today 137 (2008) 350-356.

[15] Y. Zhang, R. Yang, R. Zhao 2003,A model for analyzing the performance of photocatalytic air cleaner in removing volatile organic compounds Atmospheric Environment, 37 (2003) 3395.

[16] F. Jovic, V. Kosar, V. Tomasic, Z. Gomzi, Non-ideal flow in an annular photocatalytic reactor, Chemical Engineering Research and Design 90 (2012) 1297-1306.

[17] J. Palau, J. M. Penya-Roja, C. Gabaldon, F. J. Alvarez-Hornos, V. Martinez-Soria, Effect of pretreatments based on UV photocatalysis and photo-oxidation on toluene biofiltration performance, J Chem Technol Biotechnol. 87 (2011) 65-72.

[18] A. A. Assadi, J. Palau, Bouzaza A., D. Wolbert, a continuous air reactor for photocatalytic degradation of 3-methylbutanal : Effect of different operating parameters and Chemical degradation pathway. Chemical engineering research and design 91 (2013) 1307-1316

[19] C. Passalía, O. M. Alfano, R. J. Brandi, A methodology for modeling photocatalytic reactors for indoor pollution control using previously estimated kinetic parameters, Journal of Hazardous Materials 211-212 (2012) 357-365. 
[20] M. Salaices, B. Serrano, and H. I. de Lasa, photocatalytic conversion of organic pollutants extinction coefficients and quantum efficiencies, Ind. Eng. Chem. Res. 40 (2001) 5455-5464.

[21] A. A. Assadi, A. Bouzaza, C. Vallet, D. Wolbert, Use of DBD plasma, photocatalysis, and combined DBD plasma/photocatalysis in a continuous annular reactor for isovaleraldehyde elimination - Synergetic effect and byproducts identification, Chemical Engineering Journal 254 (2014) 124-132.

[22] H.de Lasa, B. Serrano, M. Salaices, Establishing Photocatalytic Kinetic Rate Equations: Basic Principles and Parameters, Photocatalytic Reaction Engineering (2005) 1-15.

[23] Ahlstrom Patent EP 1069950, 2000. AU 735798 US 09/467, 650; JP 2000- 542104.

[24] S. Brosillon, L. Lhomme, C. Vallet, A. Bouzaza, D. Wolbert, Gas phase photocatalysis and liquid phase photocatalysis: interdependence and influence of substrate concentration and photon flow on degradation reaction kinetics. Appl. Catal. B: Environ. 78 (2008) 232-241.

[25] B. Boulinguiez, A. Bouzaza, S. Merabet, D. Wolbert. Photocatalytic degradation of ammonia and butyric acid in plug-flow reactor: Degradation kinetic modeling with contribution of mass transfer, Journal of Photochemistry and Photobiology A: Chemistry. 200 (2008) 254-261.

[26] J.-M Herrmann, Photocatalysis fundamentals revisited to avoid several misconceptions, Applied Catalysis B: Environmental 99 (2010) 461-468.

[27] L. Zhong, F. Haghighat, Ch.-S. Lee, N. Lakdawala, Performance of ultraviolet photocatalytic oxidation for indoor air applications: Systematic experimental evaluation, Journal of Hazardous Materials 261 (2013) 130-138

[28] G. E. Imoberdorf, H. A. Irazoqui, O. M. Alfano, A. E. Cassano, Scaling-up from first principles of a photocatalytic reactor for air pollution remediation, Chemical Engineering Science 62 (2007) 793 - 804

[29] C. Vallet, Application de la photocatalyse à l'élimination des odeurs en élevages porcins. Thèse ${ }^{\circ}$ 3358. Rennes: 2006 ENSC Rennes, 149 p.

[30] D. Basmadjian, Mass Transfer and Separation Processes: Principles and Applications, Second edition, University of Toronto, Ontario, Canada. 2007.

[31] A.A. Mobarak, H.A. Farag, G.H. Sedahmed, Mass transfer in smooth and rough annular ducts under developing flow conditions. Journal of applied electrochemistry 27 (1997) 201-207. 
[32] R.H. Perry, D. Green, J.O. Maloney, Perry's chemical engineers's handbook, $7^{\text {th }}$ edition. New-York, Mc Graw-Hill Book Company, 1997.

[33] M. Hunger, G.H. Hüsken, J.H. Brouwers, Photocatalytic degradation of air pollutants from modeling to large scale application. Cem. Concr. Res. 40 (2010) 313-320.

[34] R. Yang, Y. Zhang, Q. Xu , J. Mo, 2007. A mass transfer based method for measuring the reaction coefficients of a photocatalyst. Atmos. Environ. 41(2007) 1221-1229.

[35] T. Ochiai, A. Fujishima, Photoelectrochemical properties of $\mathrm{TiO}_{2}$ photocatalyst and its applications for environmental purification, Journal of Photochemistry and Photobiology C: Photochemistry Reviews 13 (2012) 247-262.

[36] L. Zhong, F. Haghighat, modeling and validation of a photocatalytic oxidation reactor for indoor environment applications, Chemical Engineering Science 66 (2011) 5945-5954.

[37] G. Vincent, E. Schaer, P.-M. Marquaire, O. Zahraa, CFD modelling of an annular reactor, application to the photocatalytic degradation of acetone. Process Saf. Environ. Prot. 89 (2011) 35-40.

[38] S. Brosillon, L. Lhomme, D. Wolbert, Modelling of a falling thin film deposited photocatalytic step reactor for water purification: Pesticide treatment Chemical Engineering Journal 169 (2011) 216-225.

[39] M. D. Vuong 2011. Dépollution et désodorisons de l'air par photocatalyse assistée par adsorption sur charbon actif en réacteur à flux frontal continu et séquentiel. Thèse Univ. Rennes $\mathrm{N}^{\circ} 4201$. 


\section{Table}

Table 1: Values of kinetic coefficients

Table 1: Values of kinetic coefficients

\begin{tabular}{|c|c|c|}
\hline Kinetic constant & $\mathrm{k}_{1}$ & $\mathrm{k}_{2}$ \\
\hline Values $\left(\mathrm{s}^{-1}\right)$ & $(0.63 \pm 0.03) 10^{-6}$ & $(0.94 \pm 0.05) 10^{-6}$ \\
\hline
\end{tabular}




\section{Figures:}

Fig.1. Scheme (a) and sectional drawing (b) of the cylindrical photoreactor

Fig.2. Scheme (b) and sectional drawing (a) of the planar photoreactor

Fig.3. A functional diagram of pilot unit (CIAT)

Fig.4: A schematic representation and photo of photocatalytic system used in pilot unit

Fig.5: Elemental mass transfer processes involved in the photocatalytic oxidation of isovaleraldehyde with a non-porous catalyst.

Fig.6: Computed concentration of isovaleraldehydeand byproducts versus simulation time $\left([\text { Isoval }]_{0}=0.03 \mathrm{mmol} \cdot \mathrm{m}^{-3}, \mathrm{Q}=10 \mathrm{~m}^{3} \cdot \mathrm{h}^{-1}, \mathrm{~T}=25^{\circ} \mathrm{C}, \mathrm{RH}=50 \%, \mathrm{I}=24 \mathrm{~W} \cdot \mathrm{m}^{-2}\right)$

Fig.7: Variation of removal efficiency of isovaleraldehyde with the inlet concentration at different flowrates in cylindrical reactor $\left(\mathrm{T}=20^{\circ} \mathrm{C}, \mathrm{RH}=50 \%, \mathrm{I}=24 \mathrm{~W} \cdot \mathrm{m}^{-2}\right)$

Fig.8: Variation of removal efficiency of isovaleraldehyde with the inlet concentration at different flowrates in planar reactor (Air gap $=20 \mathrm{~mm}, \mathrm{~T}=20^{\circ} \mathrm{C}, \mathrm{RH}=50 \%, \mathrm{I}=24 \mathrm{~W} \cdot \mathrm{m}^{-2}$ ).

Fig.9: Comparison of simulated result of outlet concentration vs. the experimental data at different flow rates and inlet concentrations using three reactors.

Fig.10: Comparison of simulated results of $\mathrm{CO}_{2}$ 's selectivity vs. experimental data at different flowrates and inlet concentrations using three reactors. 

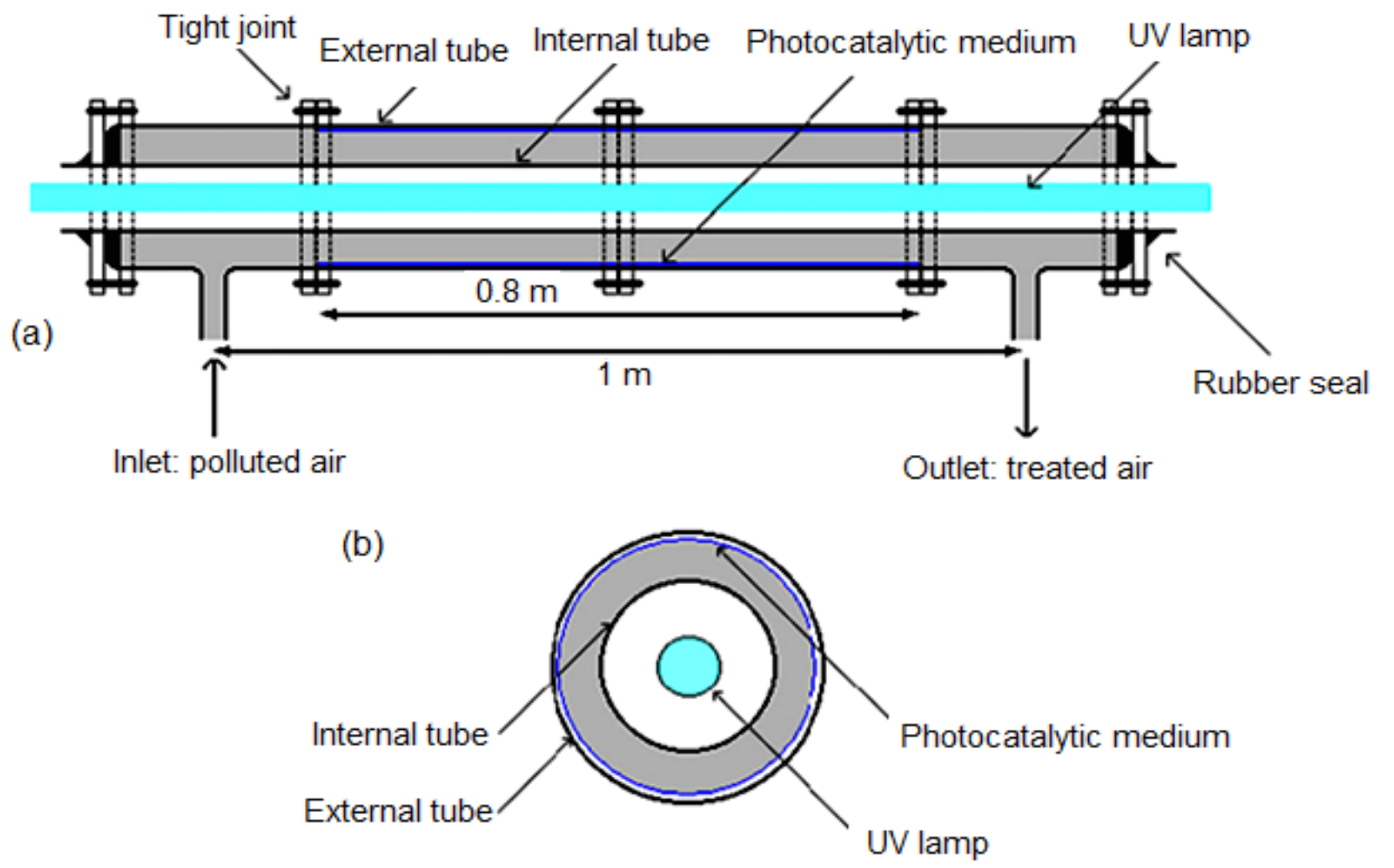

Fig. 1: Scheme (a) and sectional drawing (b) of the cylindrical photoreactor 


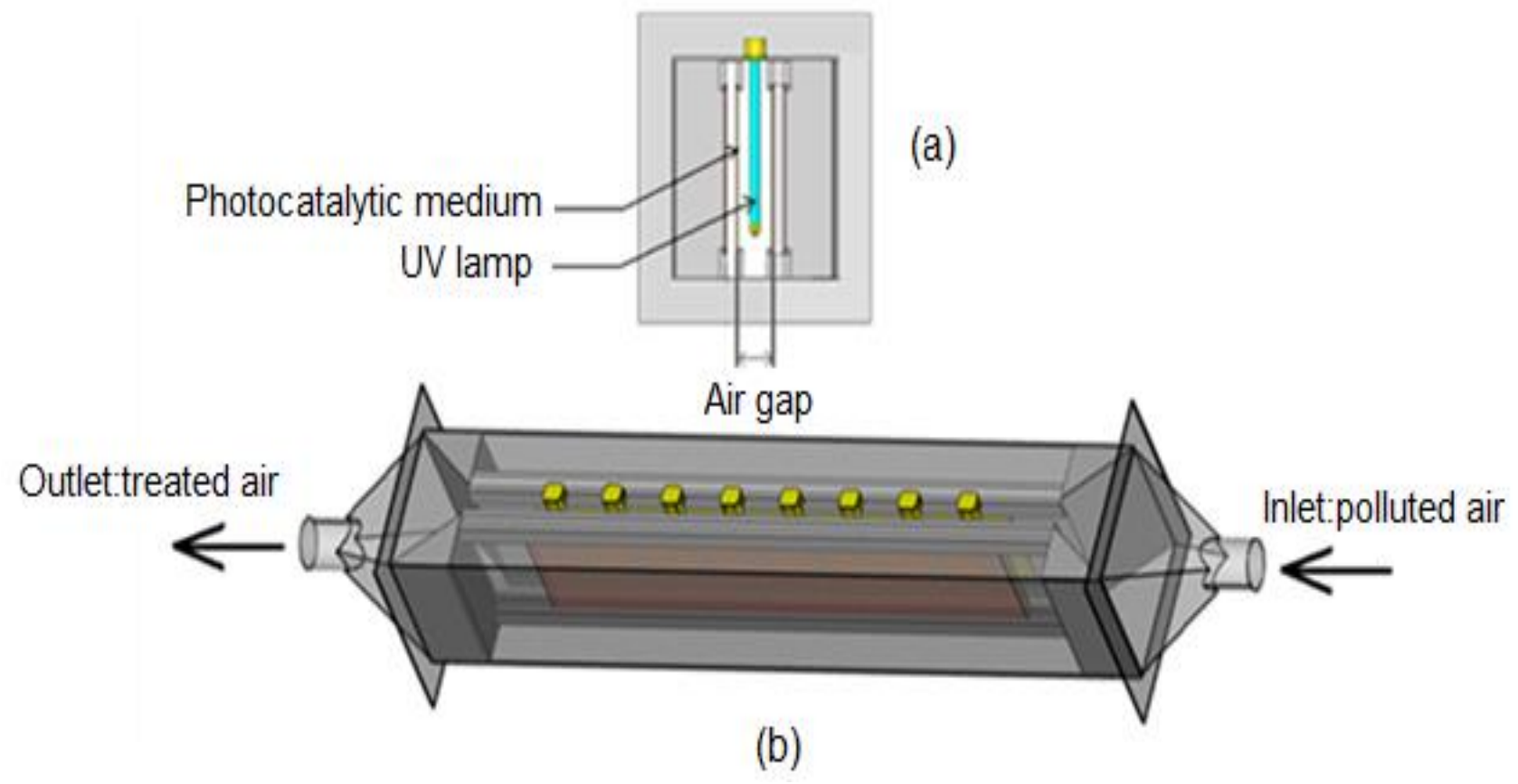

Fig.2: Scheme (b) and sectional drawing (a) of the planar photoreactor 


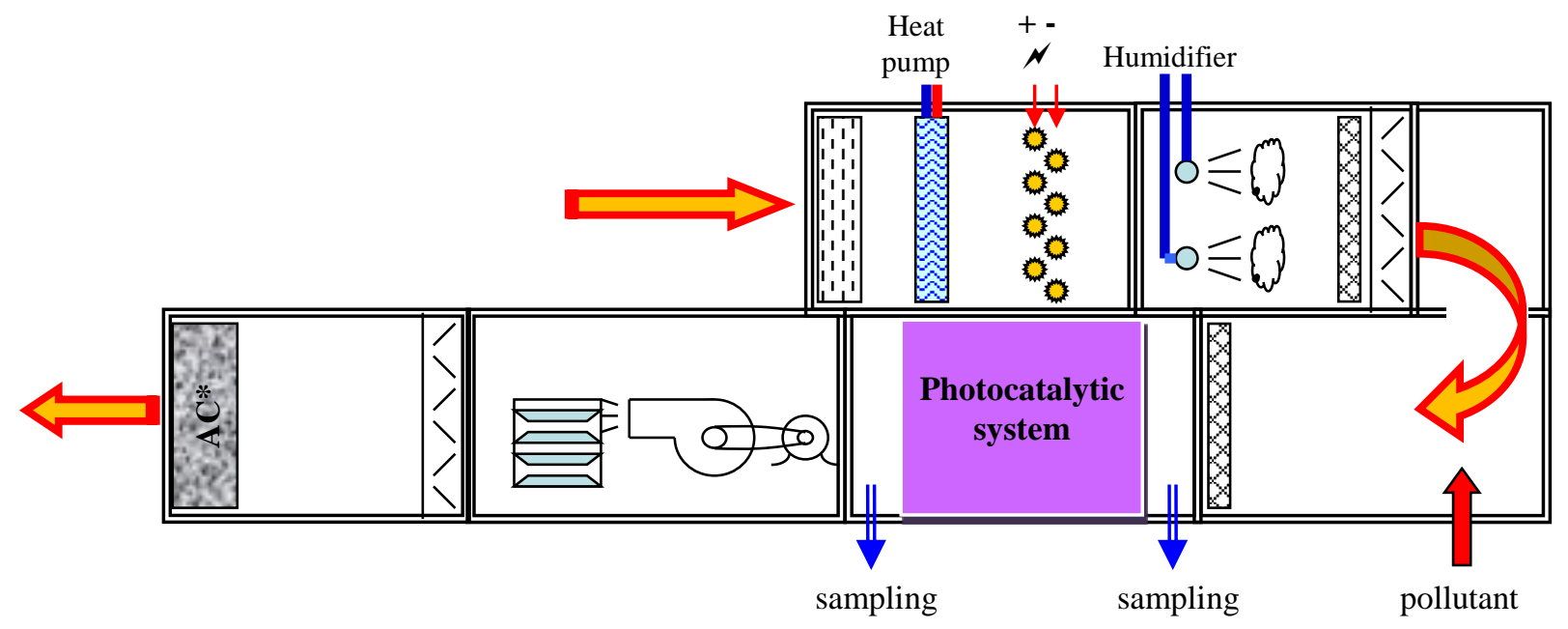

Fig.3: A functional diagram of pilot unit (CIAT) 

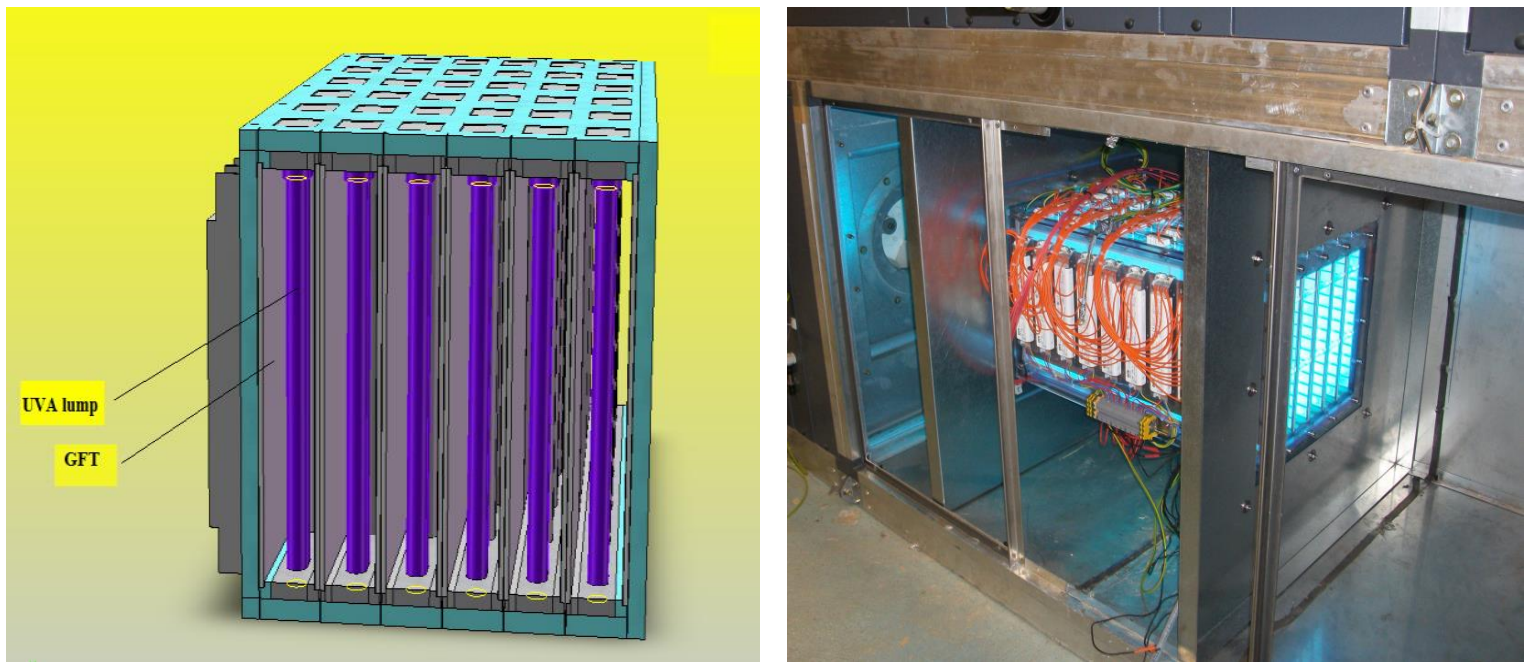

Fig. 4: A schematic representation and photo of photocatalytic system used in pilot unit 


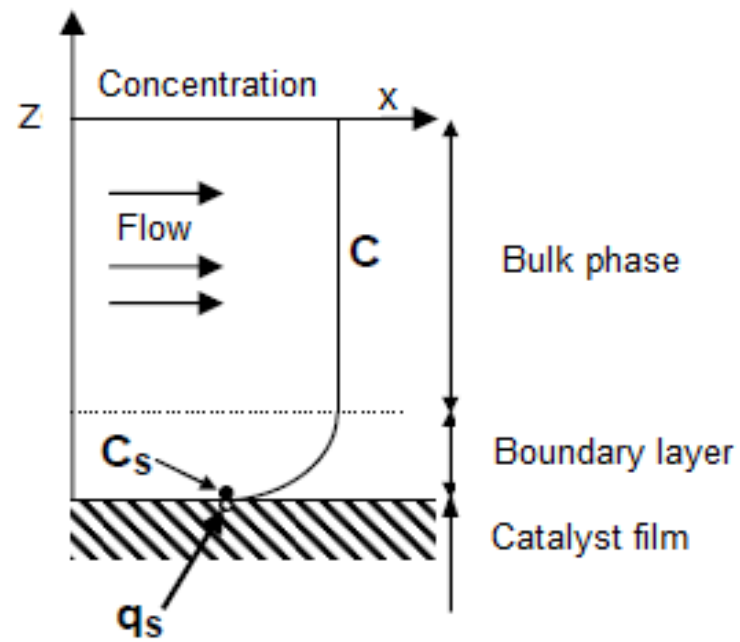

Fig. 5: Elemental mass transfer processes involved in the photocatalytic oxidation of isovaleraldehyde with a non-porous catalyst. 


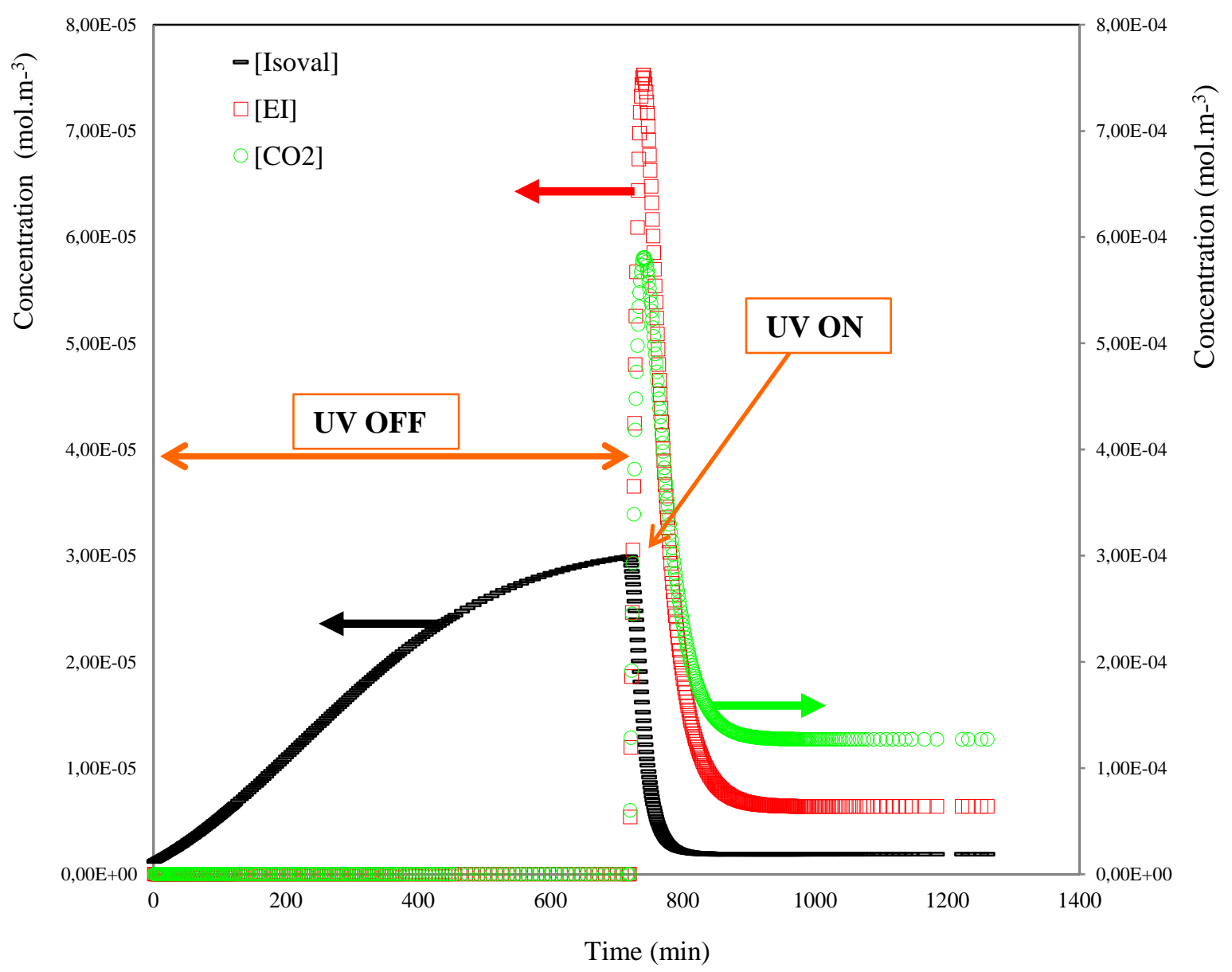

Fig.6: Computed concentration of isovaleraldehydeand byproducts versus simulation time $\left([\text { Isoval }]_{0}=0.03 \mathrm{mmol} \cdot \mathrm{m}^{-3}, \mathrm{Q}=10 \mathrm{~m}^{3} \cdot \mathrm{h}^{-1}, \mathrm{~T}=25^{\circ} \mathrm{C}, \mathrm{RH}=50 \%, \mathrm{I}=24 \mathrm{~W} \cdot \mathrm{m}^{-2}\right)$ 


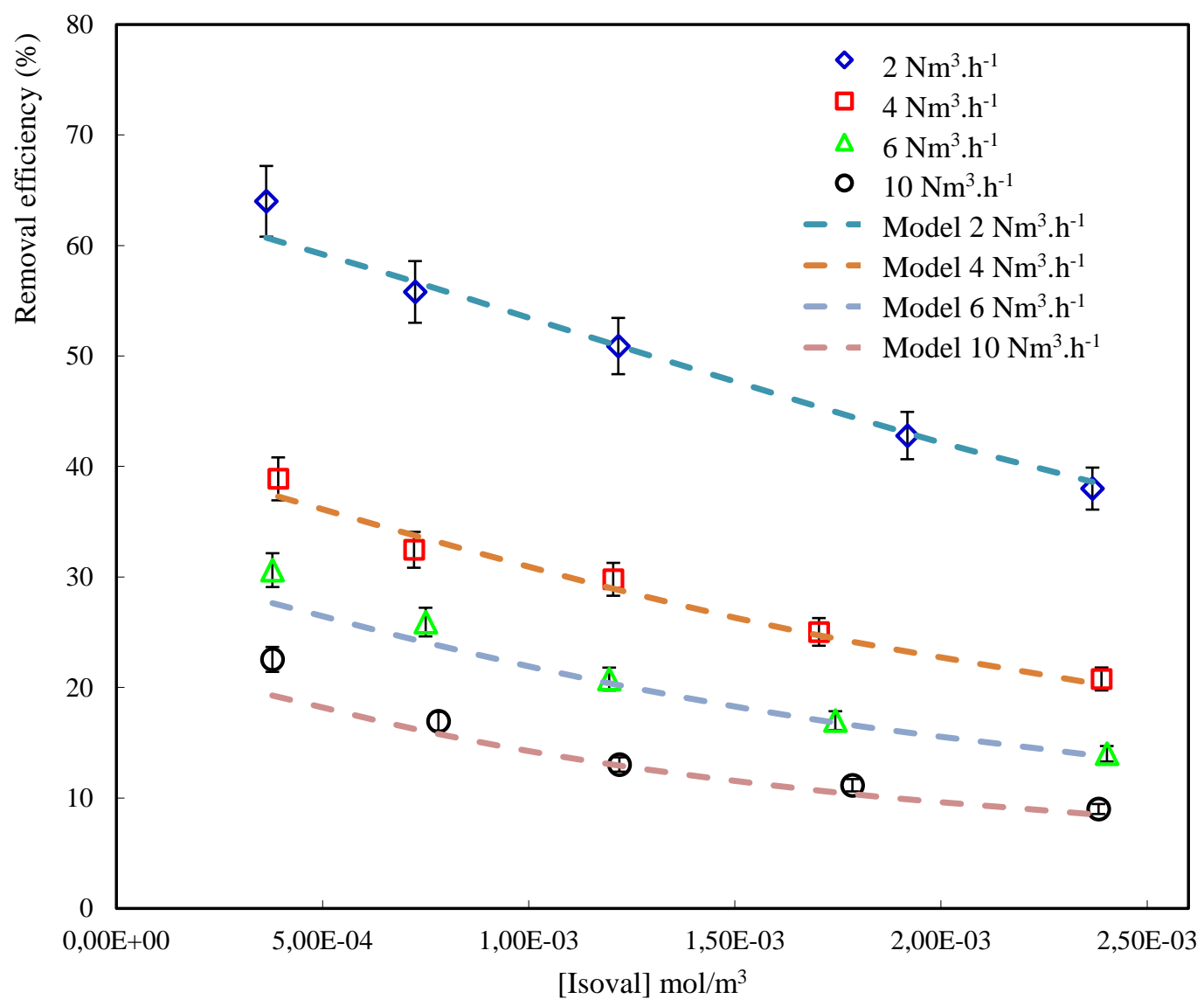

Fig. 7: Variation of removal efficiency of isovaleraldehyde with the inlet concentration at different flowrates in cylindrical reactor $\left(\mathrm{T}=20^{\circ} \mathrm{C}, \mathrm{RH}=50 \%, \mathrm{I}=24 \mathrm{~W} \cdot \mathrm{m}^{-2}\right)$ 


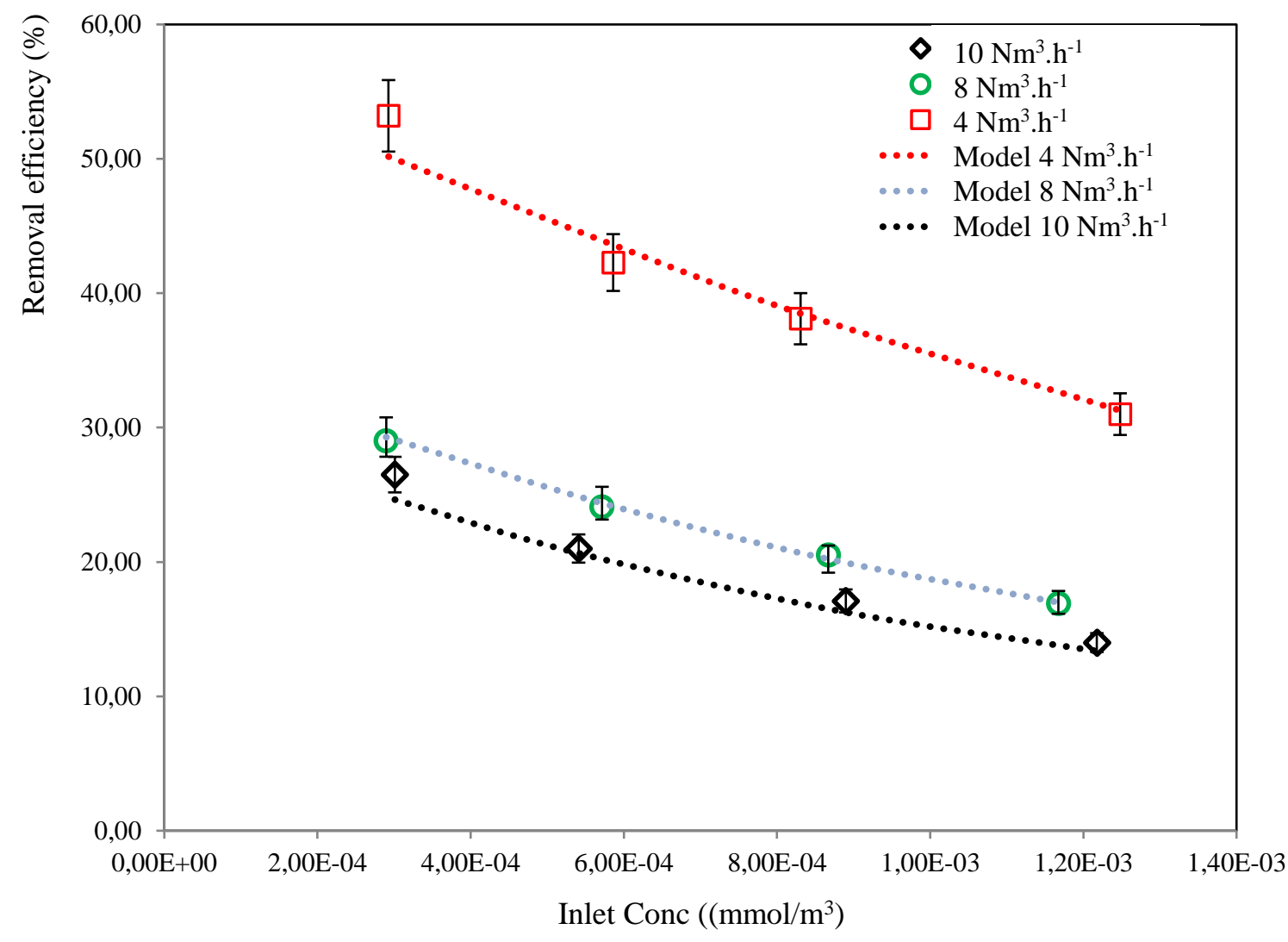

Fig. 8: Variation of removal efficiency of isovaleraldehyde with the inlet concentration at different flowrates in planar reactor (Air gap $=20 \mathrm{~mm}, \mathrm{~T}=20^{\circ} \mathrm{C}, \mathrm{RH}=50 \%, \mathrm{I}=24 \mathrm{Wm}^{-2}$ ). 


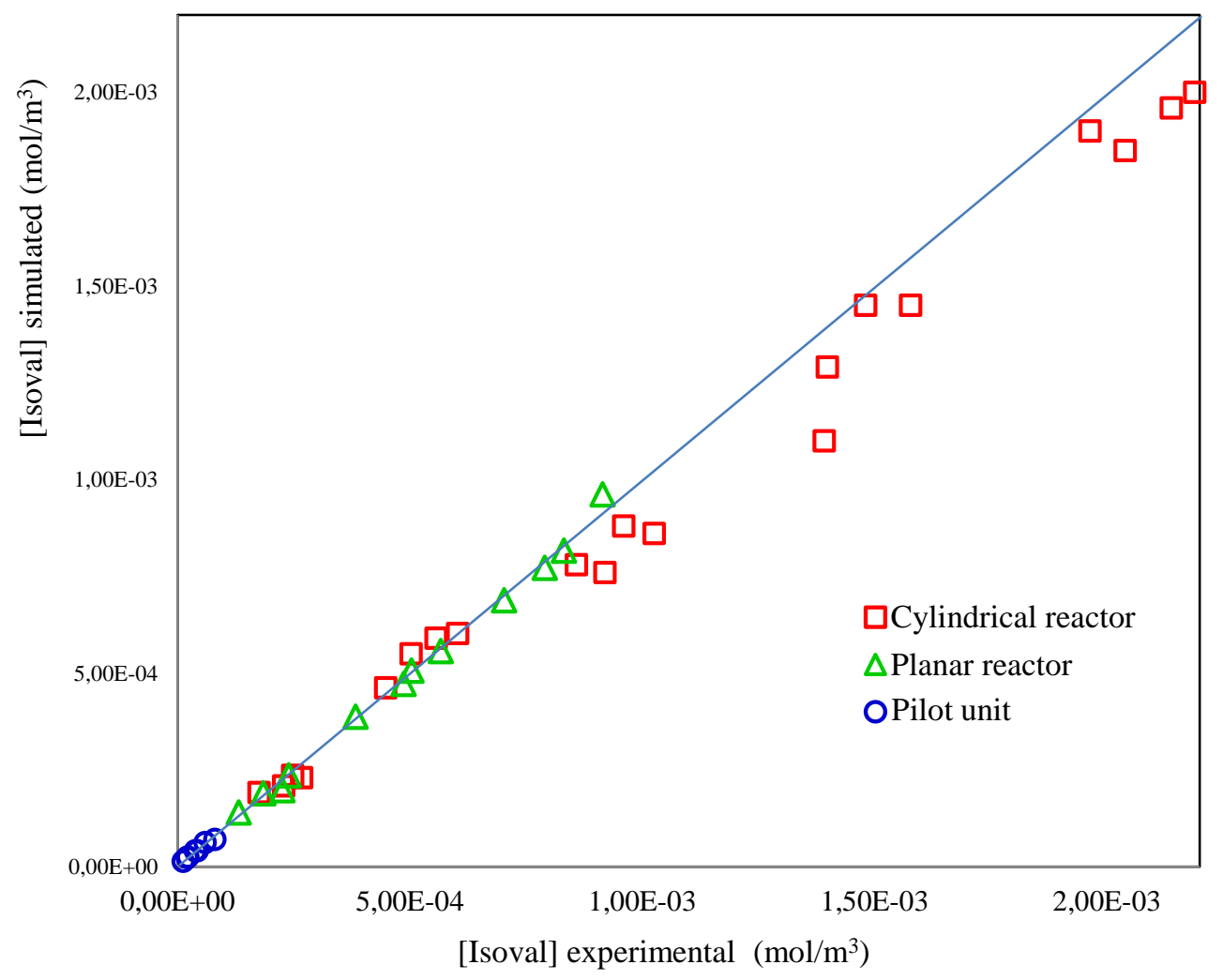

Fig. 9: Comparison of simulated result of outlet concentration vs. the experimental data at different flow rates and inlet concentrations using three reactors. 


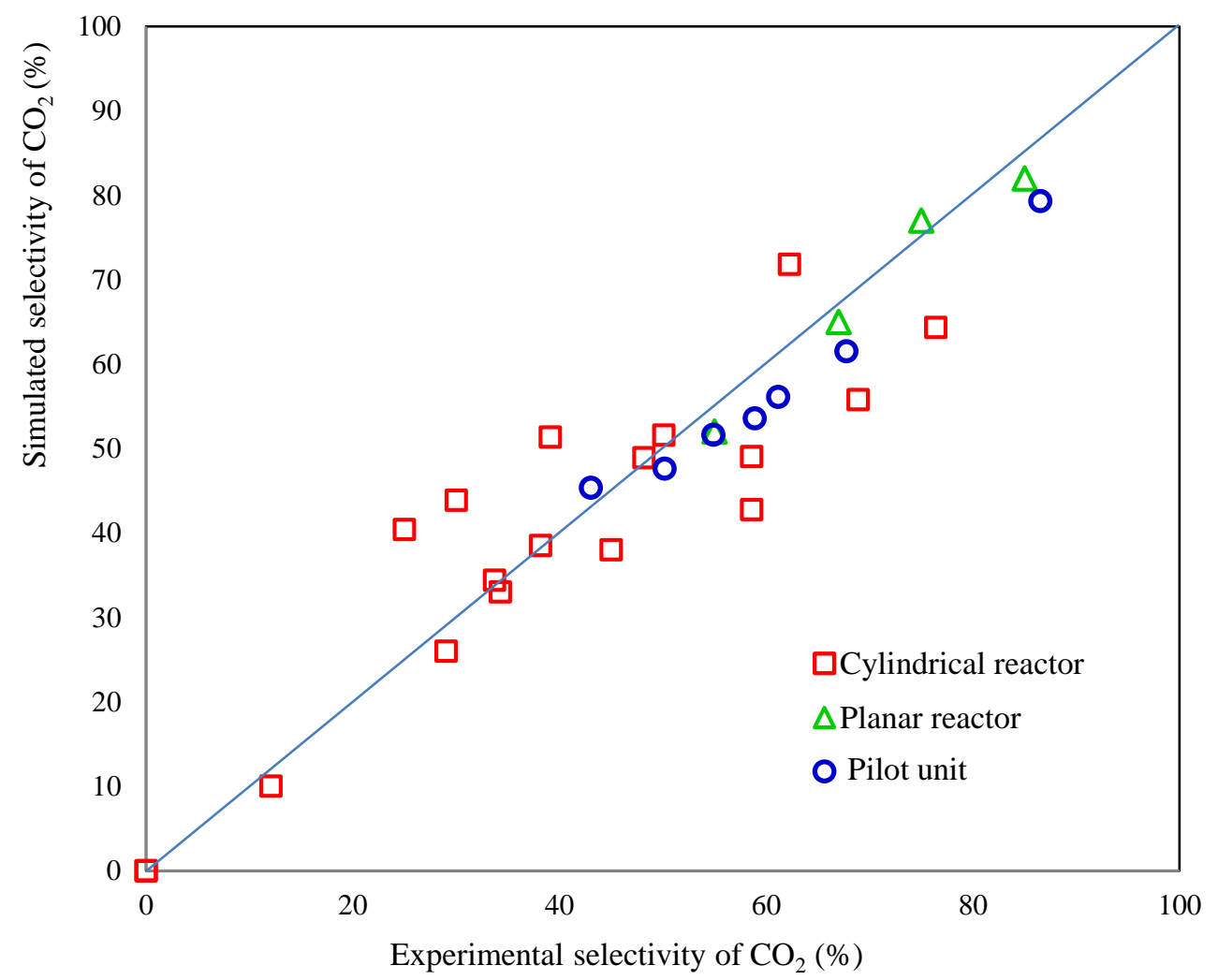

Fig. 10: Comparison of simulated results of $\mathrm{CO}_{2}$ 's selectivity vs. experimental data at different flowrates and inlet concentrations using three reactors. 